\title{
A ESCUTA DE PROFESSORES: TENSÕES E CONTRADIÇÕES SOBRE O TEMA FORMAÇÃO CONTINUADA EM CRECHES CONVENIADAS
}

\author{
Renata Cottet $^{1}$ \\ Sandra Lúcia Ferreira ${ }^{2}$
}

Resumo: Este artigo pretende discutir o atendimento de crianças entre zero e três anos, descrevendo a história da criação e da implementação de instituições de Educação Infantil considerando seus aspectos legais e normativos. Discutem-se também os encaminhamentos propostos pela sociedade civil para aplacar a precariedade e insuficiência do atendimento. Assim, é feita uma abordagem sobre a implantação de três creches conveniadas na cidade de São Paulo, destacando tensões e contradições enfrentadas por Professoras de Desenvolvimento Infantil (PDI), que falam sobre formação continuada e a relação família/escola.

Palavras-Chave: Gestão. Educação Infantil. Creches Conveniadas.

\section{LISTENING TEACHERS: TENSIONS AND CONTRADICTIONS ON THE SUBJECT CONTINUED TRAINING IN CONVENIATED CRUCES}

\begin{abstract}
This article aims to discuss the care of children between zero and three years, describing the history of the creation and implementation of early childhood institutions considering their legal and regulatory aspects. Discuss the referrals offered by civil society to placate the precariousness and inadequacy of care. In this sense, an approach is taken on the implementation of three childhood institutions $s$ in the city of São Paulo, highlighting tensions and contradictions faced by Child Development Teachers (PDI), who talk about continuing education and the family / school relationship.
\end{abstract}

Keywords: Management. Early Childhood Education. Childhood institutions

No Brasil, entende-se por Instituições de Educação Infantil escolas que recebam crianças que se encontram na faixa etária entre 0 e 5 anos: em Creche ou Instituições equivalentes ( 0 a 3 anos) e Pré-escola (4 a 5 anos). Este artigo tem foco nas creches, espaços educativos da

\footnotetext{
1 Professora universitária do curso de Licenciatura do Centro Universitário Sant'Anna (UNISANTANNA). Pós-graduada em Psicopedagogia. Mestranda no curso de Formação de Gestores Educacionais da Universidade Cidade de São Paulo (UNICID). Mantenedora da Associação de Mães e Senhoras do Parque Pan-americano (APANA).

${ }^{2}$ Docente/pesquisadora dos Programas de Pós-Graduação em Educação e em Formação de Gestores Educacionais da Universidade Cidade de São Paulo (UNICID). Pesquisadora associada do Centro Internacional de Estudos em Representações Sociais e Subjetividade-Educação (CIERS-ed).
} 


\section{REVISTA DE ADMINISTRAÇÃO EDUCACIONAL}

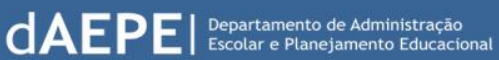

Educação Infantil e lócus privilegiado aonde ocorrem experiências importantes que começam a partir do terceiro mês de vida da criança.

\section{INTRODUÇÃO}

Entendendo a Educação Infantil como um direito da criança e dever do Estado, é preciso levar em consideração a necessidade de que esse direito seja contemplado por meio de uma educação de qualidade; por isso, a inscrição da Constituição de 1988, sobre a criança de 0 a 5 anos. A família e o Estado são responsabilizados pela educação, que deve ser promovida e incentivada com a colaboração da sociedade:

Art. $205^{\circ}$. A educação, direito de todos e dever do Estado e da família, será promovida e incentivada com a colaboração da sociedade, visando ao pleno desenvolvimento da pessoa, seu preparo para o exercício da cidadania e sua qualificação para o trabalho. (BRASIL, 1988)

Considerando a necessidade do pleno desenvolvimento, a Constituição de 1988 (BRASIL, 1988) reconhece a criança como uma pessoa que precisa de proteção contra todo tipo de negligência, discriminação, exploração, violência, crueldade, opressão e, prioritariamente, que tem direito à vida, à saúde, à alimentação, à educação, ao lazer, à profissionalização, à cultura, à dignidade, ao respeito, à liberdade, a conviver em família e na comunidade, e à proteção especial. Nesse sentido, foi criado, com a Lei $n^{\circ} 8.069$, de 13 de julho de 1990 (BRASIL, 1990), o Estatuto da Criança e do Adolescente (ECA), visando o direito constitucional da criança e do adolescente. Entre os anos de 1994 a 1996, foi publicada pelo Ministério da Educação (MEC) a Política Nacional de Educação Infantil (BRASIL, 1994) compostas por quatro documentos distintos que se completam e se integram. São eles:

1). Critérios para um atendimento em creches que respeite os direitos fundamentais das crianças;

2). Por uma política de formação do profissional de educação infantil;

3). Educação infantil: bibliografia anotada; e

4). Propostas pedagógicas e currículo em educação infantil.

Tais documentos estabeleceram as diretrizes pedagógicas visando à expansão da oferta de vagas e a promoção da melhoria da qualidade de atendimento nesse nível de ensino. O grande movimento que configura um posicionamento para a Educação Infantil vem com a Lei 
de Diretrizes e Bases da Educação Nacional - LDB nº 9.394/96. A educação infantil ganha um espaço definido na Lei (Seção II, artigos 29 e 30), passando a fazer parte da estrutura e funcionamento da educação escolar brasileira ao ser considerada como a primeira etapa da Educação Básica:

Art. 29. A educação infantil, primeira etapa da educação básica, tem como finalidade o desenvolvimento integral da criança de até 5 (cinco) anos, em seus aspectos físico, psicológico, intelectual e social, complementando a ação da família e da comunidade.

Art. 30. A educação infantil será oferecida em: I - creches, ou entidades equivalentes, para crianças de até três anos de idade; II - pré-escolas, para as crianças de quatro a seis anos de idade. (BRASIL, 1996)

Considerando o princípio constitucional de que a creche tem como objetivo educar crianças com idade entre 0 a 3 anos, o Estado Brasileiro, na qualidade de agente fomentador de políticas públicas, reconhecendo a ausência de condições para assumir a responsabilidade de gerir operacionalmente a educação de crianças pequenas, historicamente delega aos municípios a organização e sistematização do trabalho com essa faixa etária. Diz-se operacionalmente, pois, em termos de orientação, desde 1996, é com a LDB, e nas diferentes normativas - Diretrizes Curriculares Nacionais para a Educação Infantil (BRASIL, 1999) e Referencial Curricular Nacional para a Educação Infantil (BRASIL, 1998) que se processam essas operacionalidades.

Esses documentos foram elaborados pelo Conselho Nacional de Educação através da Resolução CNE/CEB no 1 (BRASIL, 1999) e do Parecer CNE/CEB nº 22 (BRASIL, 1998) e guiaram as instituições de Educação Infantil quanto à organização e coordenação da política nacional de educação, articulando os diferentes níveis e sistemas e exercendo função, normativa, bem como propondo a estrutura pedagógica e o desenvolvimento da criança, estabelecendo conceitos para a concepção de cuidado e de educação com qualidade.

Nesse sentido, a criança pequena e sua cultura passam a ser mais valorizadas. Há preocupação com seu desenvolvimento - físico/motor, psicológico, emocional, social e intelectual - e sua formação cidadã - ser ouvida, falar e ser respeitada como sujeito histórico e de direito

que, nas interações, relações e práticas cotidianas que vivencia, constrói sua identidade pessoal e coletiva, brinca, imagina, fantasia, deseja, aprende, observa, experimenta, narra, questiona e constrói sentidos sobre a natureza e a sociedade, produzindo cultura. (BRASIL, 2010) 


\section{REVISTA DE ADMINISTRAÇÃO EDUCACIONAL}

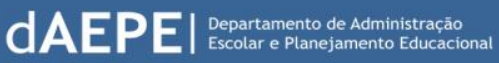

Diante dessa perspectiva, passa-se a exigir um professor também diferenciado: o de mediador entre a criança e o mundo. A família também recebe um reconhecimento: é coparticipante do processo de ensino-aprendizagem. Os conteúdos são desenvolvidos de maneira lúdica, respeitando-se a bagagem cultural de cada uma.

A compreensão sobre a importância da primeira infância é reafirmada, em 2009, Resolução $\mathrm{n}^{\circ}$, que fixa as Diretrizes Curriculares Nacionais para a Educação Infantil (BRASIL, 2009) - visando à elaboração, planejamento, execução e avaliação de propostas pedagógicas e curriculares, buscando garantir para a creche um espaço adequado de educação coletiva fora do contexto familiar.

O reconhecimento da Educação Infantil no âmbito federal se reafirma nos conteúdos do Planos Nacionais de Educação - Lei no 10.172 (BRASIL, 2001) e Lei n 13.005 (BRASIL, 2014) - documentos que determinam metas e estratégias para dez anos. Em ambos os planos, a educação das crianças de 0 a 3 anos tem destaque em meta específica com previsão de expansão do atendimento.

Apesar dos registros de melhora para a Educação Infantil, na primeira década dos anos 2000, o número de atendimento era precário. Segundo os dados do IBGE/Inep (BRASIL, 2014b), a Educação da primeira infância cresceu de 10,6\% (2001) para 21,2\% (2012).

Pode-se afirmar ainda que, segundo Ganzeli (2012), há indicadores ainda negativos que advertem sobre o pouco acesso e a qualidade do atendimento. Quanto ao acesso, segundo o autor, são exemplos a redução do atendimento de crianças em tempo integral nas creches (de 61,9\% em 2000 para 60,3\% em 2007) e a não elevação da taxa de escolarização bruta municipal em creche (em 2007, apenas 2,6\% dos municípios apresentavam taxa superior a 50\%). Em 2014, segundo dados do IBGE/INEP/FNDE (BRASIL, 2014b), apenas 24,3\% da população de 0 a 3 anos são atendidas.

\section{São Paulo: um Estado diferenciado}

Estudos mostram - Andrade (2010); Campos (2002); Campos, Rosenberg e Ferreira (1995) - que as deficiências da Educação Infantil podem ser entendidas historicamente. Em São Paulo, Estado a Educação Infantil recebeu atenção desde a década de 1930. Isso porque o então

Mário de Andrade, atuando como secretário de Cultura, cria os Parques Infantis. Adepto a 
compreender que educação, cultura e saúde são indissociáveis, assumiu, a criação e condução do Departamento de Cultura, entre 1935 e 1938. Diferentes estudos (FARIA, 1999; ABDANUR, 1994; RUBINO, 2002) indicam a preocupação de Mário de Andrade em educar uma cidade por meio do projeto dos Parques Infantis.

Tais parques, tinham uma proposta educacional, cultural e ambiental. Essas instituições foram os protótipos das atuais EMEIs - Escolas Municipais de Educação Infantil. Assim como as EMEIs, as creches também são criadas nos locais de trabalho, fundadas em indústrias têxteis e em órgãos públicos. Na década de 1930, a legislação trabalhista previa essa modalidade, mas ela nunca se tornou uma realidade na maioria das empresas.

As creches no município de São Paulo, foco de interesse deste artigo, têm em sua linha histórica instituições de acolhimento e instrução de crianças pequenas implantadas por iniciativa privada registradas no início do século XX sob a orientação da "sociedade destinada ao amparo da mulher e da criança” (FRANCO, 2009, p.30), responsável pela fundação da Creche Baronesa de Limeira, que destinava seu atendimento aos filhos das trabalhadoras que atendiam a burguesia paulistana. Nesse sentido, a origem da creche é marcada pela omissão do Estado e ausência de orientação pedagógica, sendo assumida inicial por entidades filantrópicas que inspiraram a guarda e a proteção das crianças carentes para possibilitar a inserção das mães no mercado de trabalho.

Segundo Franco (2009, p.32), a distribuição dessa organização se dá através de diferentes tipos de atendimento que se mantêm os mesmos desde 1969:

I- Centros de Educação Infantil da Rede Pública Direta (CEI direto): são as instituições próprias da rede, com funcionários da rede municipal;

II- Centros de Educação Infantil/Creches Particulares Conveniadas: são instituições que estão sob a responsabilidade das instituições conveniadas e funcionam em prédios da própria entidade a ela cedidos ou locados pela própria entidade, e que recebem recursos financeiros da Secretaria Municipal de Educação (SME);

III- Creches particulares: escolas de educação infantil de gerenciamento privado.

São Paulo incorporou a rede de creches na educação municipal no início dos anos 2000 e vem, desde então, investindo na expansão de seu atendimento. O município, - Censo Escolar de 2015 (BRASIL, 2016) - atendia mais de 240 mil crianças em turno integral 10 horas diárias em instituições diretas ou conveniadas.

O município contava, em junho de 2015, ainda de acordo com o Censo Escolar de 2015 (BRASIL, 2016), com o atendimento em creches distribuídas em 1.766 instituiçõos, divididas 
em 361 Centros de Educação Infantis Diretos, 01 Centro de Educação Municipal de Educação Infantil (CEMEI), 360 Centros de Educação Infantis Indiretos (CEII) e 1.044 Centros de Educação Infantis Conveniados (CEICs), atendendo 242.427 crianças de 0 a 3 anos.

O número elevado de escolas conveniadas associa-se ao trabalho desenvolvido pelo Terceiro setor, ou seja, conjunto de ações promovidas pela sociedade civil a fim de colaborar na execução das políticas públicas. Nesse sentido, pode-se inferir que a responsabilidade de organizar a sociedade, distribuir seus recursos e priorizar os setores que necessitam de investimentos não seja apenas do Estado. A partir do cenário que define um Estado que apresenta deficiências em cumprir com seu papel, grupos de pessoas assumem essa tarefa e priorizam a qualidade.

A Constituição de 1988, define repasse de recursos públicos para entidades filantrópicas, o que indica que deverá encontrar formas para que as parcerias convivam de forma positiva com a política de unificação com a descentralização proposta. Para Campos, Rosenberg e Ferreira (1995), a manutenção dos convênios tem sido defendida, por muitos, através do argumento de que as entidades privadas conseguem fornece os mesmos serviços que a rede pública, com custos mais baixos.

Esse panorama das escolas conveniadas também é um paliativo que tem acomodado as demandas advindas de uma necessidade social de maneira lenta e desordenada. Isso se justifica pelos fatos: no primeiro Plano Nacional de Educação (PNE), estabeleceram-se metas decenais para que, em 2011, a oferta da Educação Infantil fosse planejada para o alcance de $50 \%$ das crianças de 0 a 3 anos. Essa meta não atingida persistiu registrada no segundo PNE (2014) como um grande desafio ainda a ser alcançado.

De 1998 para 2018, passaram-se 20 anos. Nesse intervalo de tempo, apesar do reconhecimento da importância dos avanços na legislação que cerca a Educação Infantil, eles não foram suficientes para alterar o atendimento em creches. Considerando as informações disponibilizadas pelo relatório Education at a Glance 2017: OCDE - Organização para a Cooperação e Desenvolvimento Econômico (OECD, 2017), utilizando-se os dados de 2015, pode-se afirmar que somente $37 \%$ das crianças de 2 anos encontram-se matriculadas em creches.

\section{Um caso real de uma entidade privada}


Para enfrentar a luta do acesso às crianças de 0 a 3 anos, pode-se apresentar um trabalho realizado por uma entidade privada, a APANA ( Associação de Mães e Senhoras do Parque Pan-americano), administradora de creches, situadas na zona Oeste de São Paulo, no bairro de Pirituba desde 2014. Tal associação presta atendimento a 445 crianças, demonstrando a sua adequação às diretrizes e metas estabelecidas na legislação pertinente.

$\mathrm{O}$ trabalho com as creches veio de uma motivação pertinente: a comunidade sentia falta de um espaço para suas crianças pequenas. O bairro Pan-americano não era beneficiado por ambientes educacionais; algumas praças públicas ou espaços que deveriam ser praças apresentavam abandono pelo poder público. Sua comunidade trabalhadora necessitava de cuidados com a primeira infância. No final de 2012, a fundadora da APANA propôs um projeto pedagógico para ser entregue à Diretoria Regional de Ensino para estabelecer a parceria de uma creche conveniada com a instituição. Nesse projeto, a principal exigência era fazer valer o direito à creche das crianças daquela comunidade.

Durante um ano, o processo tramitou na Diretoria Regional, com impeditivos de diferentes naturezas: burocracia excessiva, falta de informação, orientações contraditórias e interesses ligados a questões políticas que envolviam ações pertinentes à vida da instituição. Somente em janeiro de 2014, depois de 2 anos do início do processo, foi inaugurada a I unidade, localizada no bairro de Pirituba, com capacidade de atender a 173 crianças e compondo um quadro de profissionais de 22 educadores e 09 funcionários administrativos.

A luta pela implantação de uma creche também tinha estímulo no pressuposto de que a APANA defendia: 1) contribuir para a liberação da mulher para o trabalho e, 2) implantar um trabalho educativo/formativo para as crianças de 0 a 3 anos. Assim, além da garantia de zelar pelo bem-estar das crianças - saúde, nutrição e segurança -, a proposta pedagógica valorizava as condições de funcionamento e de recursos materiais e humanos que propiciassem benefícios educativos para as crianças.

Assim, em julho de 2015, foi inaugurada a II unidade, localizada em outro setor de Pirituba, atendendo 163 crianças, 18 professores e 06 auxiliares administrativos. Essa unidade representou um grande desafio, pois o histórico era de uma má administração, problemas pedagógicos e estruturais. Fomos convidados pela Diretoria Regional para assumir esse equipamento. 
A III unidade aconteceu no mês de dezembro de 2015, situada no Jardim Iris, muito próxima a uma grande comunidade carente do setor 5 de Pirituba, atendendo 90 crianças, com 11 professoras, 1 cozinheira e 4 administrativos. Essa unidade chega nesse espaço para suprir uma demanda que há muito tempo aguardava por um atendimento de qualidade e integração.

Apesar dos esforços em traduzir o cotidiano de forma inovadora, os problemas que cercam as realidades dessas 03 creches são sensivelmente significativos. No que tange à infraestrutura, pode-se afirmar que os espaços educativos são alugados e adaptados para o atendimento das crianças, cuja adequação, no entanto, muitas vezes compromete o trabalho dos docentes e não privilegia o desenvolvimento das crianças de 0 a 3 anos.

A Portaria 3.479 (São Paulo, 2011) define padrões básicos de infraestrutura para Unidades de Educação Infantil que são atendidos rigorosamente, nos ambientes das três unidades pesquisadas.

1. A unidade I atende 173 crianças em prédio locado para creche que era uma fábrica de elevadores. Esta unidade dispõe no térreo de um pátio para atividades lúdicas, refeitório, cozinha, banheiros adequados para a faixa etária, uma área pequena de sol e a parte administrativa. A maior dificuldade é de não ter uma área livre, onde as crianças possam desfrutar melhor da natureza e brincar com maior liberdade.

2. A unidade II atende 161 crianças. A CEI dispõe de 11 salas, banheiros, administração, projeto do parque sonoro na área aberta, horticultura, pátio, cozinha, sala de TV. A maior dificuldade de trabalho com esse imóvel é por ser muito antigo e dispor de instalações já desgastadas.

3. Na unidade III, o espaço atende 91 crianças. No térreo, conta-se com uma sala para o berçário II, salas da Administração, Direção e Coordenação e espaço para as professoras, cozinha, banheiros, refeitório, área livre coberta para uso das atividades de leitura e festas. A maior dificuldade de trabalho dessa unidade é de não ter mais áreas abertas; a utilização do único acesso ao $1^{\circ}$ andar é realizada por uma escada, não oferecendo acessibilidade.

Quanto às dificuldades no âmbito pedagógico, pode-se afirmar que o educar contém o cuidar, o que significa, portanto, compreender que o direito à educação parte do princípio da formação da pessoa em sua essência humana e integridade. Nesse sentido, dificuldades são encontradas, nessas três creches, para estabelecer interações entre o desenvolvimento infantil e a realidade do dia a dia. Nessa perspectiva, o educar encontra-se sobre uma ação da prática diária onde os docentes necessitam de uma formação continuada para uma construção da prática 


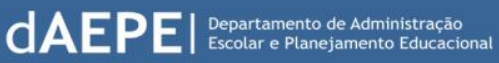

pedagógica. O reconhecimento do trabalho da equipe se diferencia da rede direta, o que proporciona uma situação de desconforto para toda a equipe, na qual o trabalho e a rotina se comparam, mas se distanciam pelas diferenças salariais e de organizações internas. Ao administrar, encontram-se dificuldades em proporcionar um ambiente mais colaborativo aos grupos, uma vez que se depara com uma carga horária extensa para os contratados em regime da - Consolidação das Leis do Trabalho - CLT (8 horas diárias), diferentemente dos concursados (6 horas diárias).

Para a comunidade externa que cerca os entornos das creches, o problema que se destaca envolve a insuficiência pelo número de vagas. As vagas oferecidas à comunidade não atendem à demanda local. Seria preciso ampliar o número de vagas para atender a todos os que procuram essas creches. As famílias interessadas pela vaga participam de uma lista organizada pela Prefeitura de São Paulo que não consegue ser zerada, pois o número de necessitados pelo serviço é maior do que as vagas disponibilizadas.

\section{Colocando em jogo as especificidades do dia a dia}

Do universo que cerca os problemas apresentados, o mais premente para a pesquisa em curso volta-se para os aspectos formativos dos professores. Nessa perspectiva de contexto, o cotidiano dos docentes apresenta inúmeras fragilidades, pois a cada criança que chega à creche ampliam-se os desafios, considerando-se as adversidades a que muitas estão submetidas.

Para conhecer o contexto pedagógico destas três creches, foi aplicado um questionário às professoras visando o levantamento de indicadores que poderiam oferecer pistas para a realização de trabalhos que orientariam a condução da formação continuada, pois na carga horária de trabalho estão previstos encontros que possibilitam o aperfeiçoamento profissional. O instrumento foi elaborado considerando uma dimensão para coleta de dados de perfil e outra para aspectos da formação pedagógica.

As análises dos dados de perfil registram que participaram da pesquisa 41 professoras que na grande maioria (43,9\%) encontra-se na faixa etária entre 31 e 40 anos de idade e quase majoritariamente $(98 \%)$ tem formação associada ao nível superior realizada no modelo presencial $(85,4 \%)$, indicando com isso, mesmo que de quantidade menor $(14,6 \%)$, a presença de professoras com formação realizada a distância. Mesmo depois de formadas, as professoras 


\section{REVISTA DE ADMINISTRAÇÃO EDUCACIONAL}

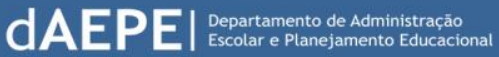

desse grupo declaram a participação em cursos de formação continuada (100\%) com vistas ao aperfeiçoamento profissional.

Para investigar de forma mais detalhada o que pensam e sabem sobre o tema Formação Continuada, foram aplicados dois conjuntos de questões objetivas e dissertativas. O primeiro tinha o propósito de delimitar a relação das professoras com esse investimento profissional, uma vez que quando inquiridas sobre a importância da formação continuada - Você considera que a formação continuada é importante para a sua prática?, as respostas foram unânimes, ou seja, $100 \%$ responderam que sim. O segundo tinha o propósito de explorar as temáticas que poderiam responder às expectativas de um trabalho formativo.

A análise do material foi pautada pela análise de conteúdos proposta por Bardin (1988). $\underline{\mathrm{O} \text { trabalho analítico teve início pelo exercício da pré-análise - leitura flutuante e em }}$ profundidade de todo o material coletado. Em seguida, forma realizadas as análises temáticas que no caso deste estudo levaram a organização de dois grupos distintos(temáticos) - Relação pessoal com a formação continuada (grupo 1) e Temáticas de interesse (grupo dois), apresentados no quadro 1, a seguir. Por fim, foram realizadas as análises inferenciais que são apresentadas no decorrer do texto.

\section{Quadro 1 - Organização das questões aplicadas}

\begin{tabular}{|c|c|}
\hline GRUPO 1 & GRUPO 2 \\
\hline Relação pessoal com a formação continuada & Temáticas de interesse \\
\hline $\begin{array}{l}\text { Você participou ao longo dos últimos } 12 \text { meses } \\
\text { de alguma formação profissional específica } \\
\text { para seu dia a dia? }\end{array}$ & $\begin{array}{l}\text { Como você acha que deve ser a formação } \\
\text { continuada para atender as necessidades oriundas } \\
\text { junto às crianças pequenas? }\end{array}$ \\
\hline $\begin{array}{l}\text { A formação profissional que você participou foi } \\
\text { fora do horário regular de trabalho? }\end{array}$ & $\begin{array}{l}\text { Você considera que as reuniões e encontros com o } \\
\text { coordenador pedagógico contribuem para sua } \\
\text { prática junto às crianças? }\end{array}$ \\
\hline $\begin{array}{l}\text { No decorrer do ano, você quis participar de } \\
\text { mais atividades de formação profissional do } \\
\text { que realmente participou? }\end{array}$ & $\begin{array}{l}\text { Quais as sugestões que você daria para } \\
\text { aperfeiçoamento na formação continuada no CEI } \\
\text { que você trabalha? }\end{array}$ \\
\hline \multicolumn{2}{|l|}{$\begin{array}{l}\text { Quais motivos impediram a sua participação em } \\
\text { outras atividades de formação continuada? }\end{array}$} \\
\hline $\begin{array}{l}\text { Como você analisa os encontros de formação } \\
\text { oferecidos pelo CEI que você atua? }\end{array}$ & \\
\hline
\end{tabular}

Fonte: as próprias autoras 
A análise do primeiro grupo de questões indica que a grande maioria das professoras declara o desejo de participar mais de cursos de formação continuada, principalmente os que são oferecidos e realizados dentro do próprio CEI, ou seja, dentro do horário de trabalho. Isso se justifica, pois, além de reconhecê-los como contribuições para a prática diária - Ótimos encontros que proporcionam ao educador mais conhecimento. (Suj.1); São oficinas objetivas, direcionadas à prática em sala de aula. (Suj.3); Muito produtivos e importantes; são informações que podemos utilizar para que possamos desenvolver nosso trabalho de uma forma ainda melhor. (Suj.14), resolvem dois impeditivos para a realização de processos formativos, ou seja, tempo e dinheiro.

O segundo grupo analisado mostra que quando sugeridas temáticas que consideram importantes para ser abordadas na formação continuada, o grupo se subdivide em temas voltados para a área pedagógica e para a relações com as famílias.

Quanto aos temas pedagógicos, os interesses se voltam para aspectos associados à Didática e para os processos relacionais com as crianças. No que se refere à Didática, pode-se afirmar que o interesse está voltado para o cotidiano do espaço educativo. Assim, as professoras pesquisadas relatam a necessidade de ampliar seus conhecimentos relacionados aos seguintes temas: artes - foco na música e no teatro, jogos e brincadeiras e "contação" de histórias. Esboçam também interesse por uma oficina para aprendizagem de confecção de brinquedos elaborados a partir de material reciclado. Quanto aos aspectos mais teóricos, indicam a necessidade de aprofundar os seguintes temas: elaboração de projetos; o brincar; o desenvolvimento motor; direito das crianças; educação ambiental; cuidar e educar; desenvolvimento infantil, entre outros.

Ainda na área pedagógica, destacam a importância dos processos relacionais: criança $\mathrm{x}$ criança e professora x criança. No primeiro (criança x criança), as respondentes destacam a importância de aprofundar informações referentes à socialização e à agressividade das crianças com foco nas “mordidas”. Quanto ao segundo (professor x criança), destacam o interesse pelos seguintes assuntos: acolhimento; higienização; autonomia; socialização; desfralde (incluindo as crianças com necessidades educativas especiais); saúde e primeiros socorros; inclusão e “dar voz as crianças". 


\section{REVISTA DE ADMINISTRAÇÃO EDUCACIONAL}

Outro tema de destaque e de interesse para o aperfeiçoamento das respondentes, está relacionado ao processo de convivência com as famílias que são atendidas pelas creches pesquisadas. Os temas destacados podem ser assim apresentados: parceria com os familiares; relação escola x família; atividades que estimulam a participação entre todos os envolvidos na educação das crianças; a postura de educador; a importância da família e da escola para o desenvolvimento infantil e o conhecimento, pela família, do trabalho desenvolvido pelos docentes.

Destaca-se, para análise, o olhar das respondentes sobre a importância do reconhecimento, pelas famílias, no que diz respeito ao o que se faz dentro do CEI. Destacam em suas falas que gostariam de aprender mais sobre:

- Atividades que estimulem a participação entre todos os envolvidos na educação das crianças. (Suj.3).

- A importância dá família e da escola para seu desenvolvimento. (Suj.5).

- A família saber e conhecer o trabalho dos docentes. (Suj.7).

Essa especificidade para trabalhar em parceria com as famílias não é novidade e nem questão específica da primeira infância. É uma demanda recorrente nos diferentes períodos de escolarização. Não há discordância sobre sua importância. O que se destaca nas análises dos resultados é a compreensão e como os pais desconhecem o significado do trabalho pedagógico para essa faixa etária. Assim, o processo relacional entre professores e pais perpassa a necessidade de se estabelecer uma ação formativa para que possam compreender a importância desata fase da vida da criança, para sua formação integral como pessoa.

Essa denúncia pode indicar a ponta de um iceberg que esconde agravantes envolvendo processos relacionais entre escola e comunidade. Quais as representações que estão sendo forjadas pelos pais e mães em relação à instituição educativa em que seus filhos(as) estão matriculados? Que compreensão eles têm em relação à importância da primeira infância?

As respondentes intuem essa necessidade de aproximação, mas também declaram a necessidade de saber mais, indicando com isso uma lacuna no processo de formação inicial (Curso de Pedagogia) que não conseguiu de forma suficientemente preparada enfrentar a construção desse processo tríade: família x criança x escola.

\section{CONSIDERAÇÕES FINAIS}


A Instituição APANA promove ações de formação em educação integral para professores e conta com profissionais de várias áreas que acrescentam conteúdos para melhorias e formação pedagógica do dia a dia da creche. Ao disponibilizar horários de planejamento, e a proposta de escutar seus professores para o aprimoramento das ações proposta, vão contribuindo para avanços, mesmo que considerados insuficientes, para a revisão da realidade deste espaço educativo.

Documentos elaborados pelo Ministério da Educação por si só não mudaram a realidade em que se encontram as políticas públicas que não são efetivas, mesmo sendo uma proposta de colaboração entre a União, os Estados, o Distrito Federal e os Municípios, no prazo de um ano de vigência deste PNE, política nacional de formação dos profissionais da educação de que tratam os incisos I, II, III do caput do art. ${ }^{\circ} 61$ da Lei no 9.394, de 20 de dezembro de 1996 (BRASIL, 1996).

É preciso ir além dos esforços de atender as normativas legais. Para que aconteça um ganho de qualidade na formação do professor - seja ela inicial ou continuada - é preciso que a Educação Básica entre na agenda de prioridade na rede das universidades públicas e privadas. Os currículos das licenciaturas pouco tratam das práticas de ensino e são distantes da realidade da escola pública de modo geral, a formação continuada se propõe a tampar os buracos deixados por anos em nossa história.

Quanto aos docentes que apresentam em sua formação o curso de Pedagogia, é preciso garantir uma prática pedagógica que possibilite compreender as especificidades do trabalho em creches. É recomendável que os cursos de Pedagogia contemplem em sua estrutura curricular a formação específica de atuação junto às crianças de 0 a 3 anos. Para os profissionais que já atuam nas creches conveniadas, reafirmamos a necessidade de uma formação continuada que considere as demandas e necessidades das próprias instituições e de suas famílias. A formação continuada apresenta-se para a gestão pedagógica e administrativa como um grande desafio; os investimentos feitos ainda são bem modestos, as políticas públicas direcionadas a esta questão se apresentam de forma ainda bem pequena; a realidade é que muitos não veem na formação um exercício de mudança no processo de desenvolvimento do educando e do educador. O não reconhecimento pela educação em nosso país faz com que a valorização desse profissional fique 


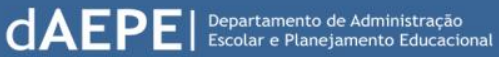

defasada; muitas vezes proporciona aos professores possibilidades escassas de trabalho e pouco reconhecimento financeiro.

\section{REFERENCIAS}

ABDANUR, Elizabeth França. Parques infantis de Mário de Andrade. Revista do Instituto de Estudos Brasileiros, São Paulo, n. 36, p. 263-270, 1994. Disponível em: <www.periodicos.usp.br/rieb/article/download/72016/75262>. Acesso em 02 jan. 2018.

ANDRADE, Lucimary Bernabé Pedrosa de. Educação infantil: discurso, legislação e práticas institucionais. São Paulo: UNESP; São Paulo: Cultura Acadêmica, 2010. Disponível em: <https://static.scielo.org/scielobooks/h8pyf/pdf/andrade-9788579830853.pdf>. Acesso em: 12 mar. 2018.

BARDIN, Laurence. Análise de Conteúdo (L. A. Reto \& A. Pinheiro, Trad.). Lisboa: Edições 70 (Trabalho original publicado em 1977) 1988.

BRASIL. [Plano Nacional de Educação (PNE)]. Plano Nacional de Educação 2014-2024 [recurso eletrônico]: Lei $n^{\circ} 13.005$, de 25 de junho de 2014, que aprova o Plano Nacional de Educação (PNE) e dá outras providências. Brasília: Câmara dos Deputados, Edições Câmara, 2014a. 86 p. (Série legislação; n. 125). Disponível em: 〈http://www.observatoriodopne.org.br/uploads/reference/file/439/documento-referencia.pdf $>$. Acesso em: em 28 maio 2018.

. Conselho Nacional de Educação. Câmara de Educação Básica. Resolução CNE/CEB n. 1 , de 07 de abril de 1999. Institui as diretrizes curriculares nacionais para a educação infantil. Brasília, DF, 1999a. Disponível em: <http://portal.mec.gov.br/cne/arquivos/pdf/CEB0199.pdf>. Acesso em: 14 jan. 2018.

Constituição [de 1988] da República Federativa do Brasil. Diário Oficial da União [da] República Federativa do Brasil, Brasília, DF, 05 de outubro de 1988. Disponível em: <http://www.planalto.gov.br/ccivil_03/constituicao/constituicao.htm>. Acesso em: 24 jan. 2018.

. Educação Para Todos (EPT). Informe Nacional Brasil - 2000/2015. Brasília, DF: MEC, 05 de junho de 2014b. Disponível em: http://portal.mec.gov.br/docman/junho-2014pdf/15774-ept-relatorio-06062014/file Acesso em: 01 fev. 2018.

Instituto Nacional de Estudos e Pesquisas Educacionais Anísio Teixeira (INP), Ministério da Educação (MEC). Censo Escolar de 2015. Brasília, DF, 2016. Disponível em: <http://portal.inep.gov.br/censo-escolar>. Acesso em: 05 jan. 2018.

Lei n. 10.172, de 09 de janeiro de 2001. Aprova o Plano Nacional de Educação (PNE). Diário Oficial da União [da] República Federativa do Brasil, Brasília, DF, 10 jan. 2001. Disponível em: 〈http://www.planalto.gov.br/ccivil_03/leis/leis_2001/110172.htm>. Acesso em: 14 maio 2018. 
Ministério da Educação. Conselho Nacional de Educação. Câmara de Educação Básica. Parecer $n^{\circ}$. 22/98, aprovado em 17 de dezembro de 1998. Diretrizes Curriculares Nacionais para a Educação Infantil. Brasília, DF, 17 dez. 1998. Disponível em: <http://portal.mec.gov.br/dmdocuments/parecer_ceb_22.98.pdf>. Acesso em: 22 fev. 2018.

. Ministério da Educação. Conselho Nacional de Educação. Câmara de Educação Básica. Resolução n. 5, de 17 de dezembro de 2009. Fixa as Diretrizes Curriculares Nacionais para a Educação Infantil. Brasília, 17 dez. 2009. Disponível em: <http://www.seduc.ro.gov.br/portal/legislacao/RESCNE005_2009.pdf>. Acesso em: 15 mar. 2018.

. Ministério da Educação. Política Nacional de Educação Infantil. Portal do MEC, Brasília, DF, $1994 . \quad$ Disponível em: <http://www.portal.mec.gov.br/seb/arquivos/pdf/pol_inf_eduinf.pdf>. Acesso em: 30 maio 2018.

- Ministério da Educação. Secretaria de Educação Básica. Diretrizes curriculares nacionais para a educação infantil. Secretaria de Educação Básica. Brasília, DF: MEC, SEB, 2010. Disponível em: 〈http://ndi.ufsc.br/files/2012/02/Diretrizes-Curriculares-para-a-E-I.pdf〉. Acesso em 03 fev. 2018.

. Presidência da República. Casa Civil. Subchefia para Assuntos Jurídicos. Lei no 9.394, de 20 de dezembro de 1996. Estabelece as diretrizes e bases da educação nacional. Brasília, DF, 23 de dezembro de 1996. Disponível em: <http://www.planalto.gov.br/ccivil_03/leis/19394.htm>. Acesso em: 23 mar. 2018.

. Presidência da República. Casa Civil. Subchefia para Assuntos Jurídicos. Lei no 10.172, de 09 de janeiro de 2001. Aprova o Plano Nacional de Educação e dá outras providências. Disponível em: <http://www.planalto.gov.br/ccivil_03/leis/leis_2001/110172.htm>. Acesso em: 23 mar. 2018.

. Presidência da República. Lei no 8069, de 13 de julho de 1990. Lex: Dispõe sobre o Estatuto da Criança e do Adolescente e dá outras providências. Brasília, DF, 1990. Disponível em: <http://www.planalto.gov.br/ccivil_03/leis/18069.htm>. Acesso em: 01 fev. 2018.

Referencial Curricular Nacional para a Educação Infantil. Ministério da Educação e do Desporto, Secretaria de Educação Fundamental. vols. 1, 2 e 3. Brasília, DF: MDE/SEF, 1998. Disponível em: <http://portal.mec.gov.br/seb/arquivos/pdf/rcnei_vol1.pdf>. Acesso em 30 jan. 2018.

Resolução CEB n. 2, de 19 de abril de 1999. Institui as diretrizes curriculares nacionais para a formação de docentes da educação infantil e dos anos iniciais do ensino fundamental, em nível médio, na modalidade Normal. Brasília, DF, 1999b. Disponível em: <http://portal.mec.gov.br/cne/arquivos/pdf/rceb02_99.pdf>. Acesso em: 22 jan. 2018. 


\section{REVISTA DE ADMINISTRAÇÃO EDUCACIONAL}

CAMPOS, Maria Malta. A legislação, as políticas nacionais de educação infantil e a realidade: encontros e desafios. In: MACHADO, Maria Lúcia de A. (Org.). Encontros e desencontros em educação infantil. São Paulo: Cortez, 2002. p. 27-33.

; ROSENBERG, Fúlvia; FERREIRA, Isabel Mendes. Creches e pré-escolas no Brasil. 2. ed. São Paulo: Cortez, Fundação Carlos Chagas, 1995.

FARIA, Ana Lúcia Goulart de. A contribuição dos parques infantis de Mário de Andrade para a construção de uma pedagogia da educação infantil. Educ. Soc., Campinas (SP), v. 20, n. 69, p. 60-91, Dez. 1999. Disponível em: $<$ http://www.scielo.br/scielo.php?script=sci_arttext\&pid=S010173301999000400004\&lng=en\&nrm=iso >. Acesso em: 20 maio 2018.

FRANCO, Dalva de Souza. Gestão de creches para além da assistência social: transição e percurso na Prefeitura de São Paulo de 2001 a 2004. Dissertação (Mestrado em Educação) Faculdade de Educação, Universidade de São Paulo, São Paulo, 2009. Disponível em: <http://www.teses.usp.br/teses/disponiveis/48/48134/tde-23092009-151933/pt-br.php>. Acesso em: 01 fev. 2018.

GANZELI, Pedro. Plano nacional de educação: implicações para a educação infantil. Revista Exitus, Belém, v. 2, n. 2, p. 77-102, jul. /dez. 2012.

NASCIMENTO; SILVA. Fineduca. Revista de Financiamento da Educação, Porto Alegre. v. 5, n. 10, 2015. Disponível em: 〈http://dx.doi.org/10.17648/fineduca-2236-5907-v5-67575 >. Acesso em: 20 abr. 2018.

OECD, "Brazil", in Education at a Glance 2017: OECD Indicators. Paris: OECD Publishing, 2017.

<http://download.inep.gov.br/acoes_internacionais/estatisticas_educacionais/ocde/education_at_a _glance/CN_Brazil_OECD_2017.pdf >. Acesso em: 02 fev. 2018.

RUBINO, Silvana. Mário e o folclore. Revista do Patrimônio Histórico e Artístico Nacional, n. 30, p.138-155, 2002.

SÃO PAULO. Portaria n. 3.479, de 08 de julho de 2011. Define padrões básicos de infraestrutura para Unidades de Educação Infantil. São Paulo: SME, 2011. Disponível em: http://www3.prefeitura.sp.gov.br/cadlem/secretarias/negocios_juridicos/cadlem/integra.asp?alt=0 9072011P\%20034772011SME>. Acesso em: 22 jan. 2018. 